TAPROBANICA, ISSN 1800-427X. October, 2011. Vol. 03, No. 02: pp. 107-109.

(C) Taprobanica Private Limited, Jl. Kuricang 18 Gd.9 No.47, Ciputat 15412, Tangerang, Indonesia.

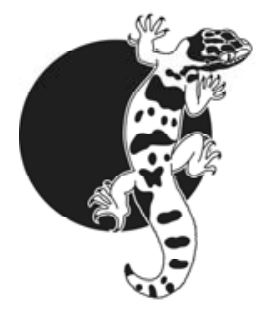

\section{Rare mammals recorded in Borneo - Malaysia}

While on a wildlife-watching trip to Sabah, Borneo, May 21 to June 5, 2011, Jeffrey Harding and I saw several rare and endangered mammal species whose distributions are not well known. Following is a list of the rarest ones with notes on location, elevation, and conservation status. Elevations were taken with a Barigo altimeter. Conservation status notes are based on IUCN (2011). Taxonomy follows Wilson \& Reeder (2005). Evidence included field notes and photographs for most species mentioned below. I offer these notes in case they may be of use in future conservation efforts or distribution studies.

\section{Order: Carnivora}

Small-toothed Palm Civet, Arctogalidia trivirgata stigmaticus: not listed as endangered, but population decreasing and range poorly known. I photographed (Fig. 1) one at night on the middle Kinabatangan River feeding on figs. Unlike the illustrations in Payne et al. (1985) and Francis (2008), this individual has thin, dark lateral bars on its sides and stripes on the side of its neck, in addition to the usual dark longitudinal stripes on the back.

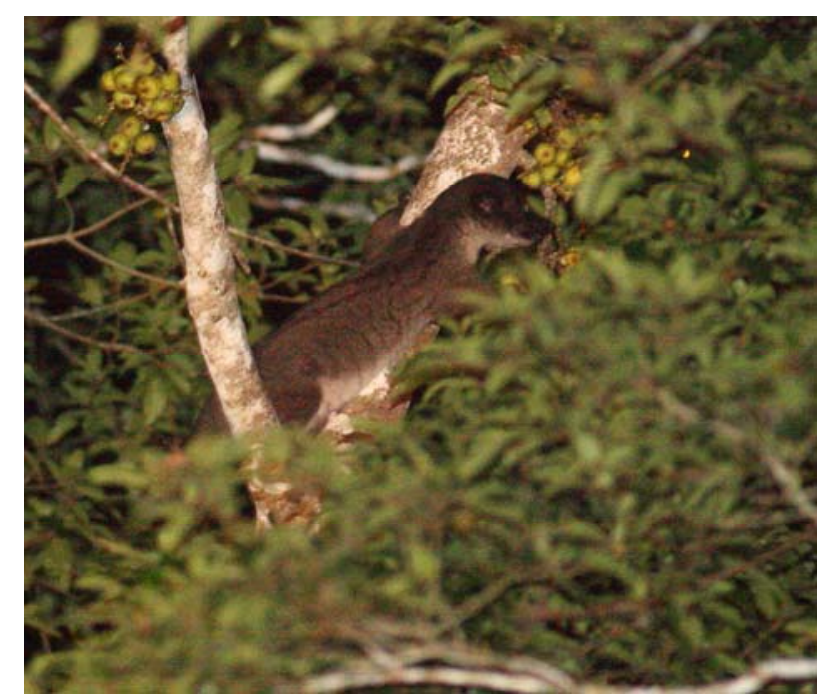

Fig. 1: Small-toothed Palm Civet

\section{Order: Erinaceomorpha}

Short-tailed Gymnure, Hylomys suillus dorsalis (endemic subspecies): Mesilau Resort, Kinabalu National Park, 1900 m (Fig. 2).

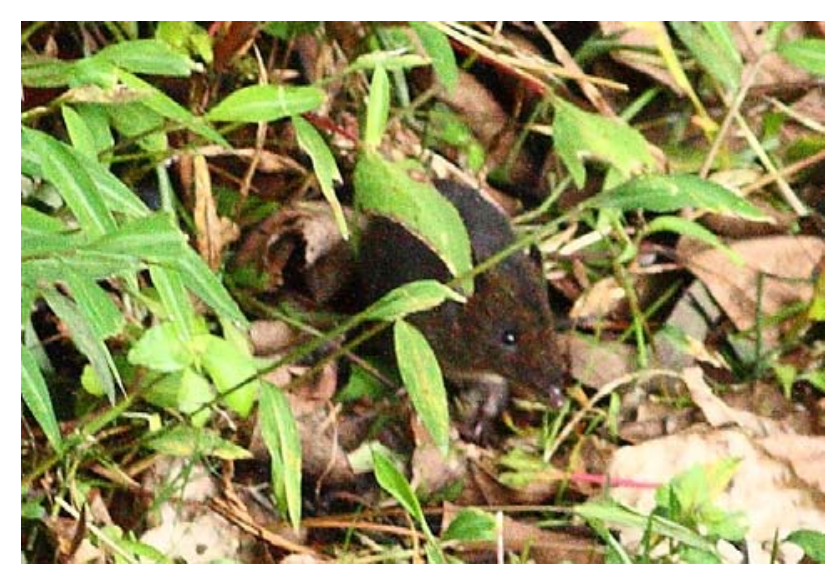

Fig. 2: Short-tailed Gymnure

\section{Order: Primates}

Besides the common and widespread Long-tailed Macaques (M. fascicularis) and Silvered Lutungs (Trachypithecus cristatus), we saw the following endangered species in the wild:

\section{Southern Pig-tailed Macaque, Macaca} nemestrina (vulnerable, population decreasing). One troop in the Kabili-Sepilok Forest Reserve (Fig. 3)

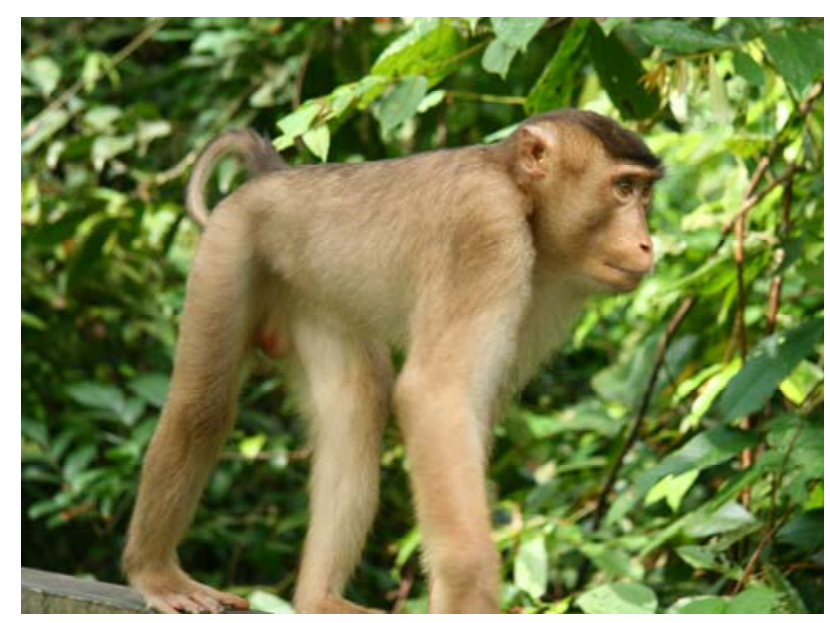

Fig. 3: Southern Pig-tailed Macaque 
Orangutan, Pongo pygmaeus (endemic, endangered): two groups along the middle Kinabatangan River: a female with a juvenile, and a lone male.

Bornean Gibbon, Hylobates müelleri funereus (endemic, endangered). One family group (male, female and juvenile) on the middle Kinabatangan River.

Proboscis monkey, Nasalis larvatus (endemic, endangered): Six troops along the middle Kinabatangan River and one troop of the alpha male, at least three adult females and several infants and juveniles on the Klias River.

\section{Order: Rodentia}

Besides many widespread sciurids (Cream-coloured Giant-squirrel, Ratufa affinis; Plaintain Squirrel, Callosciurus notatus; Prevost's Squirrel, Callosciurus prevostii; Ear-spot Squirrel, Callosciurus adamsi; Plain Pigmy Squirrel, Exilisciurus exilis; Jentink's Squirrel, Sundasciurus jentinki; Lowe's Squirrel, Sundasciurus lowii; and Bornean Mountain Ground-squirrel, Dremomys everetti), we saw or photographed:

\section{Shrew-faced Ground-squirrel, Rhinosciurus} laticaudatus: There are few records on Borneo and only one in Sabah, near Sandakan (Payne et al. 1985). I photographed (Fig. 4) one at night in the Rainforest Discovery Centre, Sepilok. The difficulty of night photography is apparent in the poor focus.

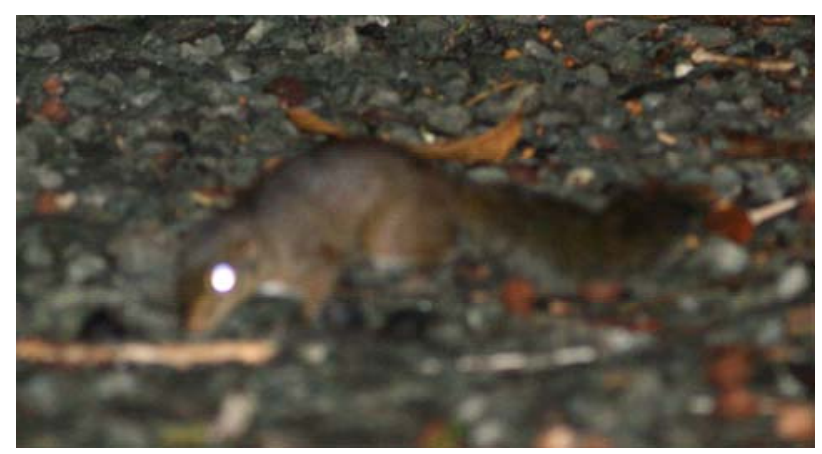

Fig. 4: Shrew-faced Ground-squirrel

Spotted Giant Flying Squirrel, Petaurista elegans banksii (endemic subspecies): In Sabah, it is only known from the Gunung Kinabalu, where we photographed (Fig. 5) it at night at $1900 \mathrm{~m}$ a.s.l. elevation, and Crocker Range. The distance and difficulty of focussing at night resulted in a poor image.

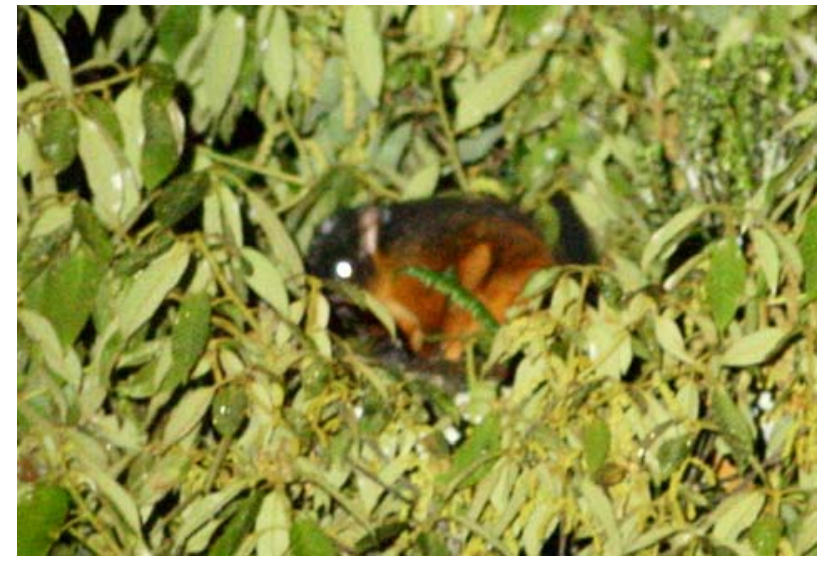

Fig. 5: Spotted Giant Flying Squirrel

We also saw the more widespread Red Giant Flying Squirrel, Petaurista petaurista, at Sepilok.

\section{Order: Scandentia}

Mountain Treeshrew, Tupaia montana baluensis (endemic subspecies): Ponduk Lowii, Kinabalu National Park, 2267 m (See the cover page of this journal).

Slender treeshrew, Tupaia gracilis (endemic): Poring Hotsprings, Kinabalu National Park, 800 m. The species is difficult to separate from the Lesser Treeshrew, Tupaia minor, without taking foot or skull measurements, but a photograph (Fig. 6) shows a long, narrow tail and colouring exactly as pictured and described by Payne et al. (1985). We believe we saw both species at this location but obtained no photographs of $T$. minor.

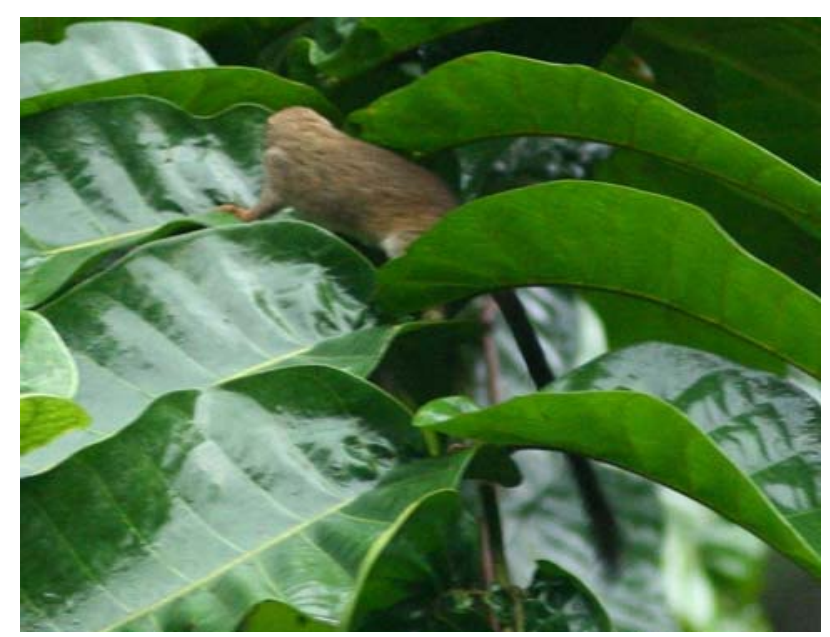

Fig. 6: Slender treeshrew

\section{Order: Artiodactyla}

While not endangered, these species are rarely seen by outsiders: At night in the Rainforest Discover Centre, we saw a Mouse-deer that our guide identified as Lesser Mouse-deer, Tragulus kanchil. 
A highlight of our trip was a flood that put our camp on the middle Kinabatangan River and much of the surrounding lowlands under water, concentrating terrestrial wildlife on a hill behind our camp. Among them was a large herd of bearded pigs, Sus barbatus.

Driving around Sabah by car, boat, and bus, it was easy to see why so many mammals are endangered. From Sepilok to the middle Kinabatangan River by car-a straight-line distance of about $80 \mathrm{~km}$ - the road was lined with palm oil plantations that often stretched to the horizon. Along the river itself, authorities, with cooperation of local people, have tried to protect a corridor of intact primary forest, with some success. Even so, in many places, the palm oil and logging companies have bull-dozed right to the river's edge.

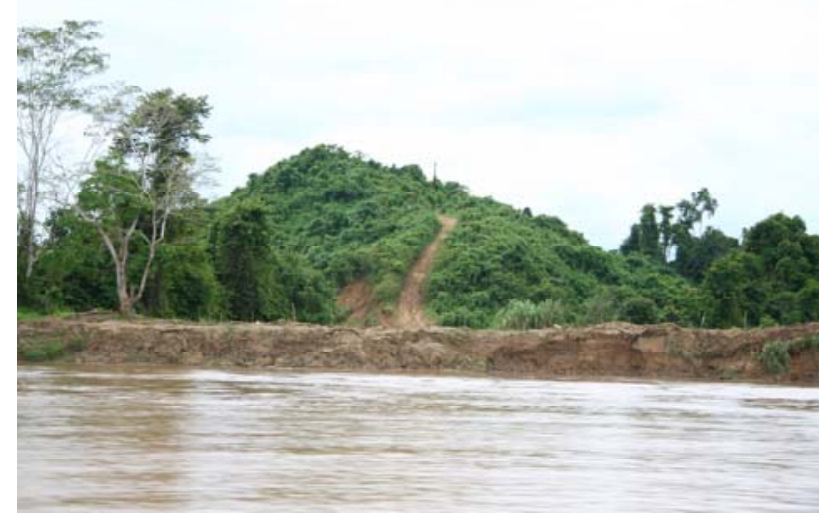

Fig. 7: Riverbank logging

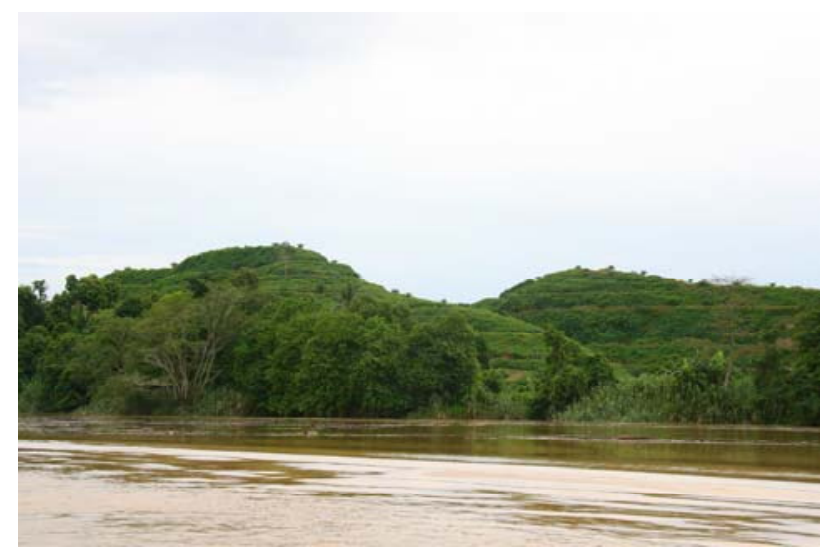

Fig. 8: Riverbank palm oil plantations

Orangutans and gibbons are obligate arborealists: neither can swim and gibbons almost never go to the ground. The several species of leaf monkeys are almost as restricted and rarely cross open ground. Even a small plot without tall trees across a connectivity corridor prevents migration and dispersal of these species. Without more rigorous protection of forest, especially in connectivity corridors, populations of these and other large mammals will surely continue their dramatic declines.

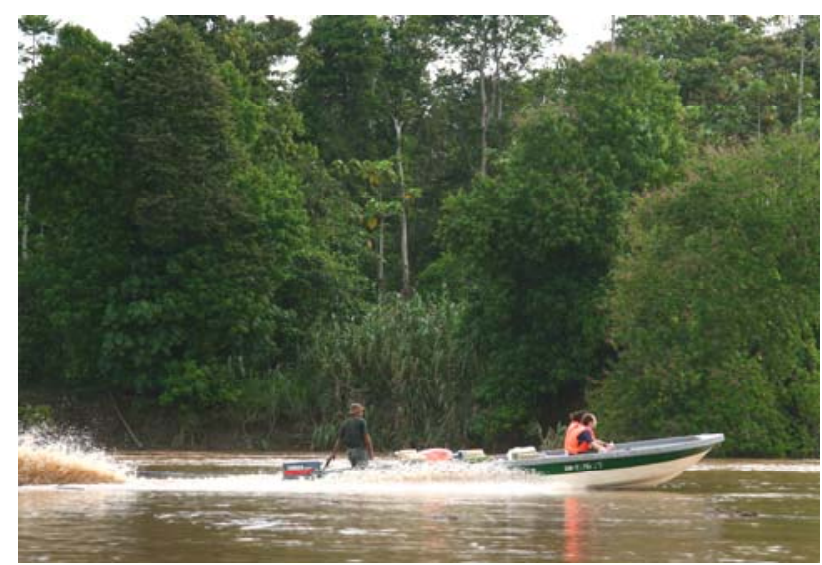

Fig. 9: Intact primary riparian dipterocarp forest on the Kinabatangan River

\section{Literature Cited}

Francis, C. M., 2008. A guide to the mammals of southeast Asia. Princeton and Oxford, Princeton University Press: 392.

IUCN, 2011. IUCN Red List of Threatened Species. Version 2011.1. <www.iucnredlist.org <http://www.iucnredlist.org>>. Downloaded on 27 July 2011.

Payne, J. B., C. M. Francis and K. Phillipps, 1985. A field guide to the Mammals of Borneo. Kuala Lumpur, Sabah Society and World Wildlife Fund: 332.

Wilson, D. E. and D. M. Reeder, 2005. Mammalian species of the world: a taxonomic and geographic reference. Baltimore, M. D. (Ed.). The Johns Hopkins University Press: 2142.

Submitted: 29 July 2011, Accepted: 29 October 2011

Lee E. Harding SciWrite Environmental Sciences Ltd., 2339 Sumpter Drive, Coquitlam, British Columbia, Canada E-mail: harding@sciwrite.ca 